\title{
Active Pharmacovigilance in Peruvian Population: Surveillance of a Timolol/Brimonidine/ Dorzolamide Ophthalmic Fixed Combination
}

This article was published in the following Dove Press journal: Clinical Ophthalmology

\author{
Homero Contreras-Salinas (D) \\ Mariana Barajas-Hernández' \\ Leopoldo Martín Baiza-Durán' \\ Alan Omar Vázquez-Álvarez ${ }^{2}$ \\ Manuel Alejandro \\ Bautista-Castro' \\ Lourdes Yolotzin \\ Rodríguez-Herrera'
}

'Pharmacovigilance Department, Laboratorios Sophia, S.A. de C.V,

Zapopan, Jalisco, México; ${ }^{2}$ School of Medicine and Health Science, Tecnológico de Monterrey, Guadalajara, Jalisco, México
Correspondence: Lourdes Yolotzin Rodríguez-Herrera

Tel +52300I 4200 ext II88

Email lourdes.rodriguez@sophia.com.mx
Purpose: In this study active pharmacovigilance was used in an uncontrolled population to enrich the safety profile and canvass the Adverse Drug Reactions (ADRs) associated with the use of a fixed combination of $0.5 \%$ timolol $+0.2 \%$ brimonidine $+2.0 \%$ dorzolamide (TBD). Methods: Active pharmacovigilance consisting of 3 follow-up calls within 60 days was used to monitor the product's safety and identify new risks by searching for unexpected ADRs and increased incidence, tolerability, drug interactions and special population-related ADRs.

Results: Ninety-four ADRs were reported by a total of 246 patients ( 0.38 ADRs/patient); all of them were classified as "mild". We found an increased risk of ADRs with a Relative Risk (RR) for simultaneous use of TBD + ophthalmic ciprofloxacin and TBD + oral atorvastatin; 2.0309 (95\% CI, 1.2467-3.3083) and 1.8864 (95\% CI, 1.0543-3.3754), respectively. Two unexpected ADRs were discovered, both of which presented belonged to the System Organ Class (SOC) of "infections and infestations" and the preferred term (PT) of "nasopharyngitis.".

Conclusion: Three safety signals were identified, two of them corresponded to an increase in the incidence of ADRs and the last one is associated with 2 unexpected ADR. Nevertheless, we found a good tolerability profile for TBD in the study population.

Keywords: adverse drug reactions, active pharmacovigilance, surveillance, glaucoma, timolol/brimonidine/dorzolamide

\section{Introduction}

The detection of risks related to marketed drugs is key in order to secure the optimal care of patients, therefore reducing the social burden derived from adverse drug reactions (ADRs) that are defined by the World Health Organization (WHO) as a response to a drug which is noxious and unintended, and which occurs at doses normally used in man for the prophylaxis, diagnosis, or therapy of disease, or for the modification of physiological function. ${ }^{1,2}$ Pharmacovigilance programs are valuable tools that allow an adequate detection of such risks, providing the information needed for the objective assessment of the risk-benefit tradeoff that inevitably accompanies the use of any commercially available medicinal product. This is accomplished by the recollection and analysis of information on ADRs. ${ }^{3}$

The WHO has defined pharmacovigilance (PV) as the "science and activities relating to the detection, assessment, understanding and prevention of adverse effects or any other possible drug-related problems". 4 It is usually developed and 
conducted by means of spontaneous reporting systems (SRS). Nevertheless, active pharmacovigilance is a broadly recognized supplement to SRS that is a type of $\mathrm{PV}$ in which active measures are undertaken to detect the presence or absence of adverse events on an ongoing basis within a defined group of people. . $^{3,5}$

The advantage of active pharmacovigilance over passive is the improved capability to identify safety signals, as well as the advantage of identifying drug interactions and other events related to medication incidents that would be difficult to identify in a passive surveillance system. ${ }^{6}$

Monitoring of drugs indicated for chronic diseases is important since safety evaluation is essential for their prolonged use. Such is the case of glaucoma, one of the leading causes of blindness worldwide, presenting as a neurodegenerative disease that results in progressive degeneration of retinal ganglion cells and their axons. Increased intraocular pressure (IOP) is one of glaucoma's main risk factors and the only one that can be modified in order to delay or prevent the progression of this disease. ${ }^{7-9}$

Generally, medical treatment begins with the administration of a single hypotensive agent, known as first-line therapy (prostaglandin analogs or beta-blockers). ${ }^{10-12}$ However, monotherapy, may be insufficient in many cases, due to an inability to achieve the target IOP. In other cases, a single drug may lose its effectiveness over time, due to tachyphylaxis. ${ }^{13,14}$

In this study, active pharmacovigilance was used in an uncontrolled population in order to enrich the safety profile and canvass the ADRs associated with the use of Krytantek Ofteno ${ }^{\circledR}$; a fixed combination of $0.5 \%$ timolol $+0.2 \%$ brimonidine $+2.0 \%$ dorzolamide (TBD) (Laboratorios Sophia, S.A. de C.V., México).

\section{Methods}

\section{Study Design}

Active pharmacovigilance was performed in Peruvian population to assess the safety of TBD under real-life conditions from 28 February 2018 (first enrolled patient) to 29 April 2020 (last completed patient) in Lima, Perú. The study was conducted according to the Declaration of Helsinki; likewise, the study's protocol and its corresponding informed consent form were reviewed and approved by an ethics committee (see Ethics approval section). During this period 294 patients were enrolled.

Since this is a real-life non-interventional study, patients prescribed TBD by an ophthalmologist (on his own initiative) were referred to a pharmacist of Laboratorios Sophia, S.A. de C.V. (Perú). Subsequently, the patients were informed about the enrollment process and invited to participate in the study. If the patient agreed to participate, the informed consent was signed. All of the admitted patients signed the informed consent before enrolling in the study. In the case of patients under 18 years old (yo), the parent or legal guardian signed the informed consent. A total of 3 follow-up calls were performed.

Initial contact call: 3 days after the enrollment process, patients were contacted and interrogated about personal data (age, gender, nationality, pregnancy or breastfeeding), characteristics of the drug and its prescription (dose, route of administration, start and end date of treatment, expiration date, batch) and data from the patient's medical history (diagnosis, concomitant drugs used and their dosage, route of administration, start of application). Additionally, the first interrogation aimed at identifying ADRs (onset date, description of intensity, ADR duration, need of treatment, rechallenge [when applicable], dechallenge [when applicable], response to dose modification [when applicable], existence of other causes different to drug application that may have explained the ADR [when applicable]) was conducted.

Second and third calls: 30 and 60 days, respectively, after the enrollment process. Second and third interrogations were aimed at identifying ADRs as mentioned above.

All data were sent to the pharmacovigilance unit of Laboratorios Sophia, S.A. de C.V (México) for data management.

\section{Data Management}

The data obtained in each of the calls were compiled in an excel document (Microsoft Office ${ }^{\circledR} 365$ ProPlus., Washington, Redmond, USA). The patients were classified as: children ( $0-12$ years), adolescents ( $>12-18$ years), adults $(>18-60)$, or geriatric $(>60)$. However, to analyze tolerability, drug interactions, and ADR incidence the total sample was used. Once the information was obtained, the severity of the ADRs was assessed using the ADR Severity Assessment Scale (Modified Hartwig and Siegel). ${ }^{15,16}$ Subsequently, the causal relationships of ADRs were assessed, in accordance to the Naranjo algorithm (Definite, Probable, Possible, Doubtful and Not assessable). ${ }^{17}$ All ADRs were listed according to MedDRA v22 (Medical Dictionary for Regulatory Activities).

The identification of new risks was carried out through 5 criteria (tolerability, drug interactions, ADRs related to 
special populations, increase of incidence and unexpected ADRs).

\section{Tolerability}

The tolerability of TBD was evaluated by measuring different parameters: ADR severity, seriousness and duration.

\section{Drug Interactions}

A bibliographic search was carried out in a database (Micromedex ${ }^{\circledR}$ IBM Corporation 2020) in order to identify drug interactions. Because there is very little information about ophthalmic drug interactions, a relative risk analysis was performed for the different drugs administered concomitantly with TBD.

\section{ADRs in Special Populations}

ADRs' incidences in adults and geriatrics were compared, as well as the difference between males and females to observe TBD's behavior in different groups of an uncontrolled population.

\section{Increase of Incidence and Unexpected ADRs}

An analysis comparing the frequency of the ADRs of our study with the reported in two reference databases for drug information (Micromedex ${ }^{\circledR}$ IBM Corporation 2020 and MedicinesComplete ${ }^{\circledR}$ "Martindale Drug reference" The Royal Pharmaceutical Society 2020) was performed in order to determine whether TBD increases the frequency of ADRs over individual drug administration.

\section{Statistical Analysis}

Quantitative variables were described as a mean \pm SD and qualitative variables were described as frequencies and percentages. A chi-square test was performed to compare proportions and Fisher's exact for small-sized samples. To determine the risk of the use of TBD with concomitant therapies, Relative Risks (RRs) and corresponding Confidence Intervals (CIs [95\%]) were performed. In this study, our statistical significance was set at a p-value $\leq 0.05$. All statistical analyses were performed using SPSS (version 21; SPSS, Inc., Chicago, IL, USA).

\section{Results}

\section{Patient's Characteristics}

A total of 294 patients signed the informed consent; however, the percentage of patients not contacted was $16.3 \%$ $(n=48)$ due to: call not answered $(58.3 \%, n=28)$, the phone number did not correspond to the person who signed the informed consent $(31.3 \%, \mathrm{n}=15)$, the phone number did not exist $(10.4 \%, n=5)$. A total of 246 patients were contacted; 132 women (children: $\mathrm{n}=1 ; 9$ yo, adults: $\mathrm{n}=51$; mean $49.6 \pm 7.1$ yo, geriatric: $n=80$; mean $72.0 \pm 7.5$ yo) and 114 men (adults: $\mathrm{n}=45$; mean $48.3 \pm 9.6$ yo, geriatric: $\mathrm{n}=69$; mean $69.2 \pm 6.9$ yo), no adolescents nor pregnant or breastfeeding women were enrolled in the study. The main indication for TBD prescription was "glaucoma" $75.2 \%$ $(n=185)$, followed by "ocular hypertension" $18.3 \%(n=$ 45) (Table 1). One hundred sixty-six patients presented comorbidities during the study, being hypertension the most frequent with an incidence of $45.5 \%$, followed by dry eye in $41.1 \%$ of patients, diabetes mellitus in $6.5 \%$, hyperlipidemia in $2.4 \%$, and "other" in $4.5 \%$.

\section{Adverse Drug Reactions}

A total of 246 patients reported 94 ADRs (0.38 ADR/ patient), distributed into different age groups: adults 0.45 $\mathrm{ADR} /$ patient and geriatric $0.34 \mathrm{ADR} /$ patient; no ADRs were reported in children. A comparative analysis was conducted to determine whether ADRs in different age

Table I Characteristics of the Patients

\begin{tabular}{|l|c|}
\hline Age Groups & $\mathrm{n}(\%)$ \\
Children & $\mathrm{I}(0.4)$ \\
Adolescent & $0(0)$ \\
Adult & $96(39.0)$ \\
Geriatric & $\mathrm{I} 49(60.5)$ \\
\hline Sex & $\mathrm{n}(\%)$ \\
Female & $132(53.7)$ \\
Male & $\mathrm{II}(46.3)$ \\
\hline ADRs & $\mathrm{n}(\%)$ \\
Yes & $94(38.2)$ \\
No & $152(61.8)$ \\
\hline Medical Prescription & $\mathrm{n}(\%)$ \\
Glaucoma & $185(75.2)$ \\
Ocular Hypertension & $45(18.3)$ \\
Post-Surgical & $14(5.7)$ \\
Other & $2(0.8)$ \\
\hline Comorbidity & $\mathrm{n}(\%)$ \\
Yes & $166(67.5)$ \\
No & $80(32.5)$ \\
\hline Concomitant Therapy & $\mathrm{n}(\%)$ \\
Yes & $\mathrm{I} 25(50.8)$ \\
No & $121(49.2)$ \\
\hline
\end{tabular}




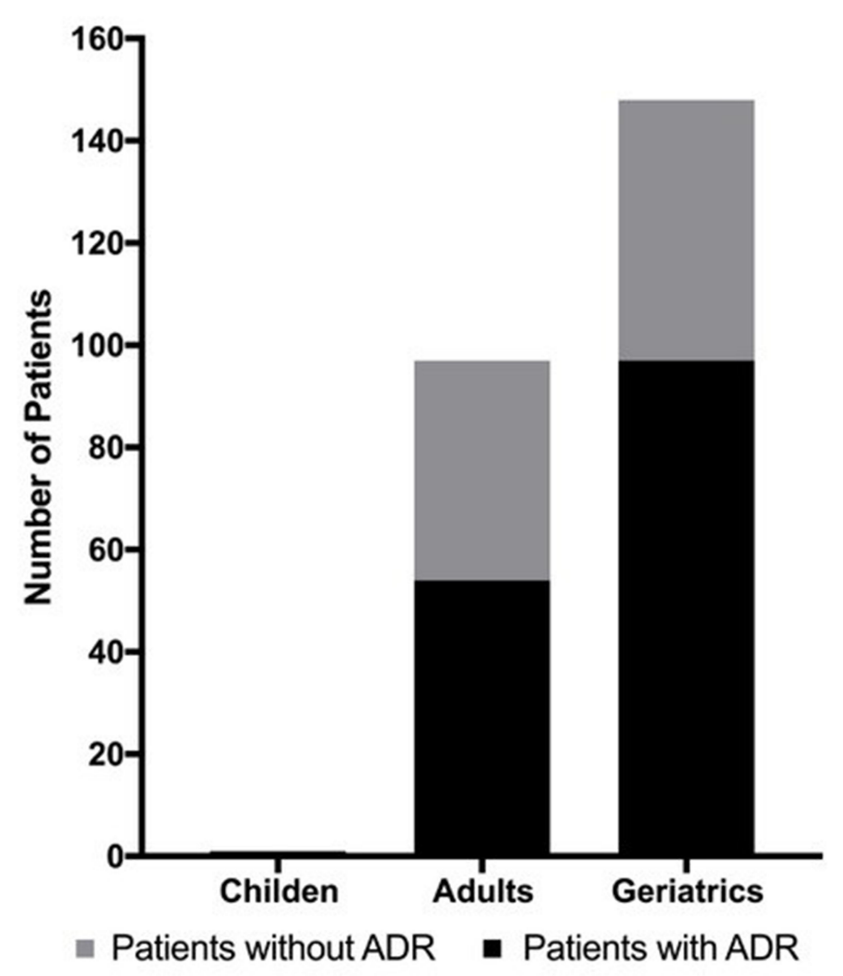

Figure I Adverse drugs reactions of different age groups of TBD treatment.

groups had a similar incidence: adults 43 ADRs ( $n=96)$, geriatrics 51 ADRs ( $\mathrm{n}=149)$ (Figure 1). No significant differences were found through the Chi Square test $\left(\mathrm{X}^{2}{ }_{(1)}\right.$ $=2.4142, \mathrm{p}=0.120242$ ).

All the reported ADRs were classified as "mild". The causality of ADRs was classified as: "probable" in $86.2 \%$ of cases, followed by "possible" in $9.6 \%$ and as either "doubtful" or "definite" in $2.1 \%$ each (Table 2). The recovery time after an ADR was $0-1$ minute $(n=48$; $51.1 \%),>1-2$ minutes $(\mathrm{n}=16 ; 17.0 \%),>2-3$ minutes $(\mathrm{n}=10 ; 10.6 \%),>3-5$ minutes $(\mathrm{n}=11 ; 11.7 \%)$, or $>5$ minutes $(\mathrm{n}=9 ; 9.6 \%)$.

The 94 reactions identified in this study were coded in the standardized data terminology "MedDRA" System Organ Class (SOC), finding that the most frequent was "eye disorders" (92\%), followed by "nervous system disorders" (4\%), "infections and infestations" (2\%), "investigations" (1\%) and "gastrointestinal disorders" (1\%). In the same way, the ADRs were catalogued according to Preferred Term (PT) being the most common "eye irritation" $(80.9 \%)$ followed by "vision blurred" (5.3\%), "eye pruritus" $(3.2 \%)$, "dysgeusia" (3.2\%), "nasopharyngitis" $(2.1 \%)$, and "blood pressure decreased", "ocular hyperemia", "eye pain", "dry mouth", "headache", "somnolence" (1\%) each (Table 3 ).

It was determined that $50.8 \%$ of the patients enrolled in the study used other drugs simultaneously with TBD. The most frequent drugs and their respective related ADR frequency were as follows: latanoprost $[n=40(16.2 \%)]$, prednisolone $[n=20(8.1 \%)]$, carmellose $[n=19 \quad(7.7 \%)]$ (Figure 2). No drug interactions were found in the literature. Nevertheless, we performed a relative risk (RR) analysis of the previously mentioned drugs and their respective ADRs. An increase in the risk of ADRs with a RR for the simultaneous use of TBD + ophthalmic ciprofloxacin and of TBD + atorvastatin 2.0309 (95\% CI, 1.2467-3.3083) and 1.8864 (95\% CI, 1.0543-3.3754), respectively, was found; this risk was not present in the remaining drugs $(\mathrm{RR} \leq 1)$ (Figure 2$)$.

The bibliographic review showed the differences between TBD against individual active ingredients wherein no statistically significant difference was found for 4 ADRs: "eye irritation", "eye pruritus", "vision

Table 2 Causality Assessment of the ADRs

\begin{tabular}{|c|c|c|c|c|c|}
\hline ADRs & Definite & Probable & Possible & Doubtful & Total \\
\hline Blood pressure decreased & - & - & $\mathrm{I}(\mathrm{I} \%)$ & - & I (I\%) \\
\hline Nasopharyngitis & - & - & $\mathrm{I}(\mathrm{I} \%)$ & $\mathrm{I}(\mathrm{I} \%)$ & $2(2.1 \%)$ \\
\hline Somnolence & - & I (I\%) & - & - & I (I\%) \\
\hline Headache & - & I (I\%) & - & - & I (I\%) \\
\hline Dysgeusia & - & - & I (I\%) & $\mathrm{I}(\mathrm{I} \%)$ & $2(2.1 \%)$ \\
\hline Dry mouth & - & - & I (I\%) & - & I (I\%) \\
\hline Eye irritation & $2(2.1 \%)$ & 70 (75\%) & $4(4.3 \%)$ & - & 76 (80.9\%) \\
\hline Eye pruritus & - & $3(3.2 \%)$ & - & - & $3(3.2 \%)$ \\
\hline Vision blurred & - & $4(4.3 \%)$ & I (I\%) & - & $5(5.3)$ \\
\hline Ocular hyperemia & - & $\mathrm{I}(\mathrm{I} \%)$ & - & - & I (I\%) \\
\hline Eye pain & - & I (I\%) & - & - & $\mathrm{I}(\mathrm{I} \%)$ \\
\hline Total & $2(2.1 \%)$ & 81 (86.2\%) & $9(9.6 \%)$ & $2(2.1 \%)$ & $94(100 \%)$ \\
\hline
\end{tabular}


Table 3 ADRs of TBD vs Reported by Individual Active Ingredient

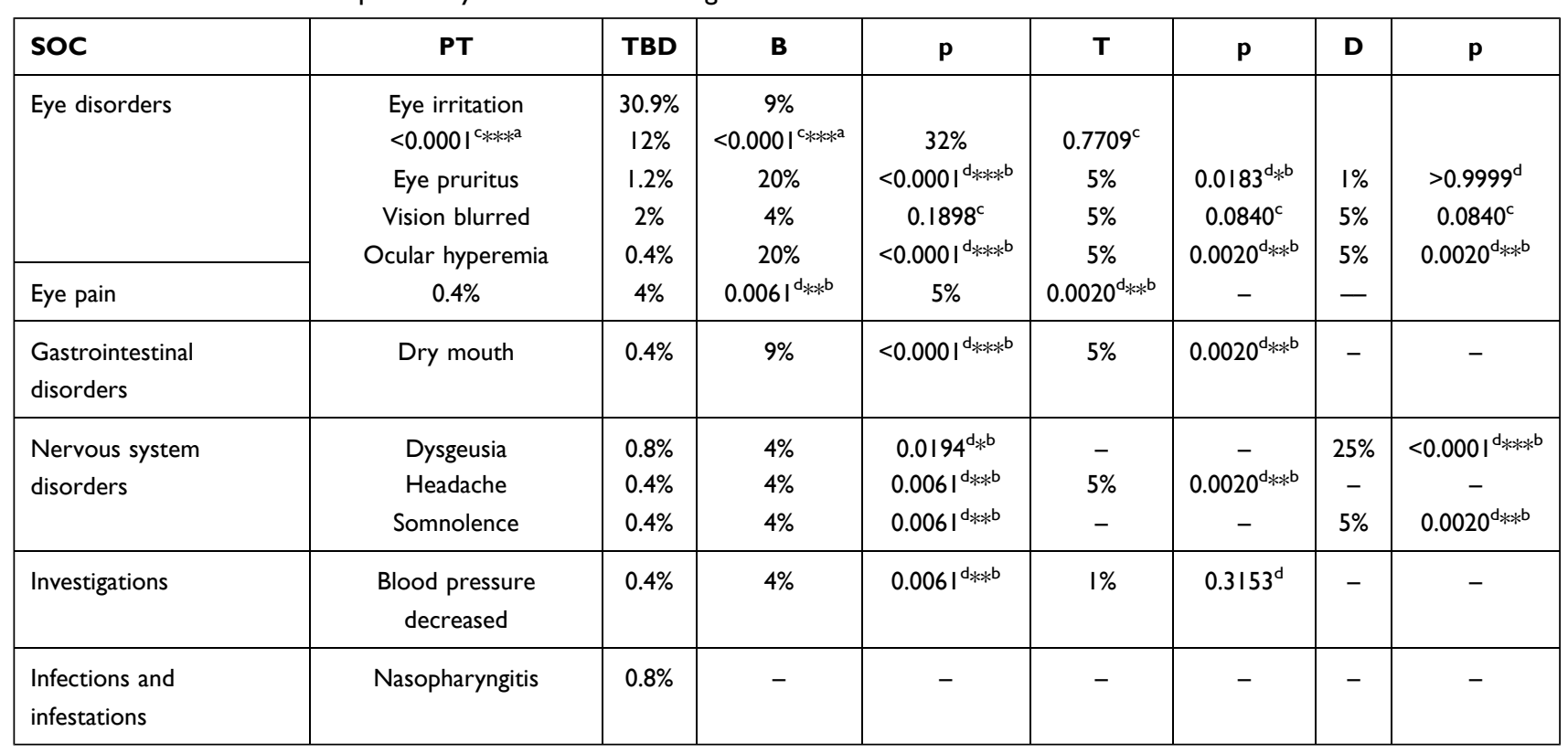

Notes: Significance, ${ }^{*}<0.05, * * p<0.01, * * * p<0.001$. ${ }^{a}$ The statistical significance is above expected to TBD. ${ }^{b}$ The statistical significance is below expected to TBD. ${ }^{\mathrm{c}}$ Pearson Chi-square test. ${ }^{\mathrm{d}}$ Fisher's exact test.

Abbreviations: SOC, System Organ Class; PT, preferred term; TBD, timolol/brimonidine/dorzolamide fixed combination; T, timolol; B, brimonidine; D, dorzolamide.

blurred" and "blood pressure decreased" between TBD in connection to any of the individual active drugs. However, for the ADRs: "eye hyperemia", "eye pain", "dry mouth", "dysgeusia", "headache" and "somnolence" was found statistically significant in TBD in relation to each individual active, likewise, according to the databases' reference comparison for the active ingredients of TBD, two unexpected adverse reactions were discovered according to the databases (Table 3). Both ADRs presented belong to the SOC of "infections and infestations" and a preferred term (PT) of "nasopharyngitis" with the causalities "possible" and "doubtful" (Table 2).

\section{Discussion}

No drug interactions between TBD and the concomitant drugs used by the patients included in this study were described in the literature. ${ }^{18-20}$ Nevertheless, the available bibliographic information of drug interactions is focused on their systemic effects rather than on their on-site effect when used simultaneously with other ophthalmic medications. It is for this reason that a relative risk (RR) analysis of the drugs used by the patients during TBD treatment was performed. The results exposed 2 drugs with increased risk: ciprofloxacin and atorvastatin.

No information was found in the literature describing the association between ciprofloxacin and increased ADR risk with any of the active ingredients of TBD. However, the only ADR associated to the use of both ciprofloxacin and TBD was "eye irritation" which, interestingly, is the most frequent ADR associated to the use of ophthalmic ciprofloxacin $^{21}$ and this could explain the increased frequency of this ADR due to the eye irritation produced by the concomitant drug per se.

Another drug associated to an increased risk of presenting ADRs while used concomitantly with TBD in this study was oral atorvastatin. Similar to ciprofloxacin, no information was found in the literature of an increased incidence to ADRs for this combination; however, oral administration of 3-hydroxy-3-methyl-glutaryl-coenzyme A (HMG CoA) reductase inhibitors as atorvastatin has been involved in several ophthalmic ADRs. ${ }^{22-25}$ This might increase the incidence of ADRs in ophthalmic drugs such as TBD.

In a clinical study of 56 patients carried out by BaizaDurán et al (2012) the incidence of adverse events (AE) for TBD according to severity was: mild $(\mathrm{n}=1)$, moderate $(\mathrm{n}=1)$ and severe $(\mathrm{n}=1)$; while for a combination it was: mild $(n=3)$ and severe $(n=2) \cdot{ }^{26}$ In the current study of 246 patients, all the ADRs were considered mild $(n=94)$. Given the uncontrolled conditions in which the active pharmacovigilance study took place, it is relevant to highlight that no increase in ADRs' severity was shown in such conditions. 


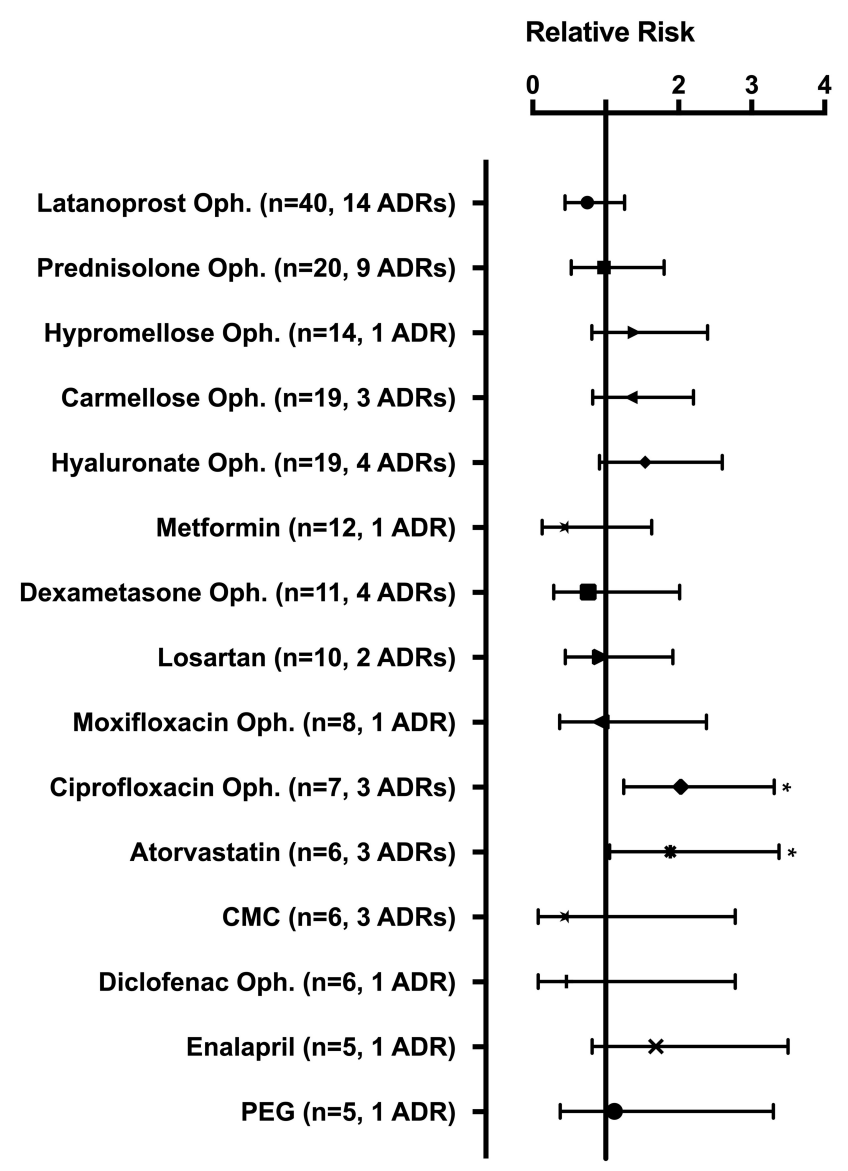

Figure 2 Drugs used concomitantly with TBD and their relative risk (RR) of adverse drug reactions (ADRs).

Note: *Relative risk $>$ I.

Abbreviations: Oph, ophthalmic; CMC, carboxymethylcellulose; PEG, polyethylene glycol..

A comprehensive literature search was conducted and the results showed that no restriction or increased frequency of ADRs were found with the use of TBD in different age groups, ${ }^{4,26-28}$ this agrees with what was identified in the present study where no significant difference in incidence of ADRs between adults vs geriatrics was found.

During the database search, the incidence of nasopharyngitis secondary to the use of any of the active components of TBD was not found. ${ }^{18-20,27}$ Nevertheless, this ADR had already been reported in the literature. ${ }^{28-31}$ Bradford-Hill criteria (Strength of Association, Consistency, Specificity, Temporality, Biological Gradient Dose-Response, Plausibility, Coherence, Experiment, Analogy) was performed, ${ }^{32}$ and the data revealed that there is an association of the use of timolol and "nasopharyngitis", however more information will be required to propose nasopharyngitis as a new risk associated with the use of timolol.
A bibliographic analysis of incidence comparing the TBD's ADRs to the expected adverse reactions ${ }^{18-20,27,33}$ showed that the triple combination (TBD) administration does not increase the incidence of the ADRs previously described in the literature for any of the three individual drugs. According to the information observed in this study, a decrease in the incidence of several ADRs was identified in comparison to the administration of these drugs in an individual fashion.

\section{Limitations of Study}

The data collection method through a direct interview to the patient could be limited by the patient's medical knowledge; and the detection of reactions may be limited. Likewise, the databases collected information from various sources like articles, meta-analyses from multiple countries, and we cannot guarantee that ADRs were adapted to the same conditions as our study. Also, the evaluation of the long-term safety profile of TBD use was not performed.

\section{Conclusions}

In this study, we found a good tolerability profile for TBD in the study population and no special population-related ADRs were detected. On another hand, no increased incidence of ADRs was found compared to the literatureavailable information. However, three safety signals were identified, two of them corresponding to an increase in the incidence of an ADR after the use of TBD in concomitance with ophthalmic ciprofloxacin and oral atorvastatin; and finally, secondary to the unexpected presentation of two ADRs, "nasopharyngitis".

\section{Data Sharing Statement}

The data presented in this study are available on request from the corresponding author.

\section{Ethics Approval}

This study was approved by the "Comite Institucional de Bioética (CIB), Vía libre”, located in Lima, Perú (Approval Number 4207, Dic-18-2018). This study was conducted in compliance with international guidelines and in accordance with strictest international ethical regulations for research.

\section{Acknowledgments}

This study was sponsored by Laboratorios Sophia, S.A. de C.V. (Zapopan, Jalisco, México). The sponsor provided 
support in the form of salaries for authors ( $\mathrm{HCS}, \mathrm{MBH}$, LMBD, MABC and LYRH), but did not have any additional role in the data collection. The authors thank Alejandra Sánchez Rios, MD for the medical writing support.

\section{Disclosure}

Homero Contreras-Salinas, Mariana Barajas-Hernández, Leopoldo Martín Baiza-Durán, Manuel Alejandro Bautista-Castro, Lourdes Yolotzin Rodríguez-Herrera are employees of Laboratorios Sophia S.A. de C.V. The authors report no other conflicts of interest in this work.

\section{References}

1. WHO. Pharmacovigilance: ensuring the safe use of medicines; Published 2004. Available from: https://apps.who.int/iris/bitstream/ handle/10665/68782/WHO_EDM_2004.8.pdf;sequence=1. Accessed August 25, 2020

2. Caster O, Juhlin K, Watson S, Norén GN. Improved statistical signal detection in pharmacovigilance by combining multiple strength-ofevidence aspects in vigiRank. Drug Saf. 2014;37(8):617-628. doi:10.1007/s40264-014-0204-5

3. Mann M, Mengistu A, Gaeseb J, et al. Active surveillance versus spontaneous reporting for first-line antiretroviral medicines in namibia: a cost-utility analysis. Drug Saf. 2016;39(9):859-872. doi:10. 1007/s40264-016-0432-y

4. WHO. The importance of pharmacovigilance; Published 2002. Available from: https://apps.who.int/iris/handle/10665/42493. Accessed August 15, 2020

5. Li X, Li H, Deng J, et al. Active pharmacovigilance in China: recent development and future perspectives. Eur J Clin Pharmacol. 2018;74 (7):863-871. doi:10.1007/s00228-018-2455-z

6. Moses C, Celi LA, Marshall J. Pharmacovigilance: an active surveillance system to proactively identify risks for adverse events. Popul Health Manag. 2013;16(3):147-149. doi:10.1089/ pop.2012.0100

7. Weinreb RN, Khaw PT. Primary open-angle glaucoma. Lancet. 2004;363(9422):1711-1720. doi:10.1016/S0140-6736(04)16257-0

8. Grzybowski A, Och M, Kanclerz P, Leffler C, De MCG. Primary open angle glaucoma and vascular risk factors: a review of population based studies from 1990 to 2019. J Clin Med. 2020;9:3. doi:10.3390/jcm9030761

9. Musch DC, Gillespie BW, Niziol LM, Lichter PR, Varma R. Intraocular pressure control and long-term visual field loss in the collaborative initial glaucoma treatment study. Ophthalmology. 2011;118(9):1766-1773. doi:10.1016/j. ophtha.2011.01.047

10. European glaucoma society. Terminology and guidelines for glaucoma, 4th edition - chapter 3: treatment principles and options supported by the EGS Foundation: part 1: foreword; introduction; glossary; chapter 3 treatment principles and options. $\mathrm{Br}$ J Ophthalmol. 2017;101(6):130-195.

11. Conlon R, Saheb H, Ahmed IIK. Glaucoma treatment trends: a review. Can J Ophthalmol. 2017;52(1):114-124.

12. Moshirfar M, Parker L, Birdsong OC, et al. Use of rho kinase inhibitors in ophthalmology: a review of the literature. Med Hypothesis, Discov Innov Ophthalmol J. 2018;7(3):101-111.
13. Sharma S, Trikha S, Perera SA, Aung T. Clinical effectiveness of brinzolamide $1 \%$-brimonidine $0.2 \%$ fixed combination for primary open-angle glaucoma and ocular hypertension. Clin Ophthalmol. 2015;9:2201-2207. doi:10.2147/OPTH.S72380

14. Sampaolesi R, Sampaolesi JR, Zárate J. The Glaucomas: Volume II Open Angle Glaucoma and Angle Closure Glaucoma. 1st ed. Springer-Verlag Berlin Heidelberg; 2014.

15. Hartwig SC, Siegel J, Schneider PJ. Preventability and severity assessment in reporting adverse drug reactions. Am J Hosp Pharm. 1992;49(9):2229-2232.

16. Petrova G, Stoimenova A, Dimitrova M, Kamusheva M, Petrova D, Georgiev O. Assessment of the expectancy, seriousness and severity of adverse drug reactions reported for chronic obstructive pulmonary disease therapy. SAGE Open Med. 2017;5:2050312117690404. doi:10.1177/2050312117690404

17. Naranjo A, Busto U, Sellers E, et al. A method of estimating the probability of adverse drug reactions. Clin Pharmacol Ther. 1981;30:239-245. doi:10.1038/clpt.1981.154

18. Timolol. Micromedex; Published 2020. Available from: https://www. micromedexsolutions.com/. Accessed September 25, 2020

19. Brimonidine. Micromedex; Published 2020. Available from: https:// www.micromedexsolutions.com/. Accessed August 15, 2020

20. Dorzolamide. Micromedex; Published 2020. Available from: https:// www.micromedexsolutions.com/. Accessed September 16, 2020

21. Ciprofloxacin. Micromedex; Published 2020. Available from: https:// www.micromedexsolutions.com/. Accessed August 20, 2020

22. Mizranita V, Pratisto EH. Statin-associated ocular disorders: the FDA and ADRAC data. Int J Clin Pharm. 2015;37(5):844-850. doi:10.10 07/s11096-015-0128-x

23. Fraunfelder FW, Richards AB. Diplopia, blepharoptosis, and ophthalmoplegia and 3-hydroxy-3-methyl-glutaryl-CoA reductase inhibitor use. Ophthalmology. 2008;115(12):2282-2285. doi:10.1016/j.ophtha. 2008.08.006

24. Machan CM, Hrynchak PK, Irving EL. Age-related cataract is associated with type 2 diabetes and statin use. Optom Vis Sci off Publ Am Acad Optom. 2012;89(8):1165-1171. doi:10.1097/OPX.0b01 $3 \mathrm{e} 3182644 \mathrm{~cd} 1$

25. Schlienger RG, Haefeli WE, Jick H, Meier CR. Risk of cataract in patients treated with statins. Arch Intern Med. 2001;161 (16):2021-2026. doi:10.1001/archinte.161.16.2021

26. Baiza-Durán LM, Llamas-Moreno JF, Ayala-Barajas C. Comparison of timolol $0.5 \%+$ brimonidine $0.2 \%+$ dorzolamide $2 \%$ versus timolol $0.5 \%+$ brimonidine $0.2 \%$ in a Mexican population with primary open-angle glaucoma or ocular hypertension. Clin Ophthalmol. 2012;6:1051-1055. doi:10.2147/OPTH.S33578

27. The Royal Pharmaceutical Society. MARTINDALE drug reference; Published 2020. Available from: https://about.medicinescomplete.com/ publication/martindale-the-complete-drug-reference/. Accessed May 4, 2020

28. Gómez-Aguayo F, Paczka JA, Leñero-Córdova R, et al. A Phase III Randomized clinical trial of a $0.5 \%$ timolol $+0.2 \%$ brimonidine + $2.0 \%$ dorzolamide fixed combination, preservative-free ophthalmic solution vs. $0.5 \%$ timolol $+0.2 \%$ brimonidine $+2.0 \%$ dorzolamide fixed combination in patients with controlled pri. Ophthalmol Ther. 2018;7(1):145-156. doi:10.1007/s40123-018-0128-8

29. Barnebey HS, Robin AL. Adherence to fixed-combination versus unfixed travoprost $0.004 \% /$ timolol $0.5 \%$ for glaucoma or ocular hypertension: a randomized trial. Am J Ophthalmol. 2017; 176:61-69. doi:10.1016/j.ajo.2016.12.002

30. Altafini R, Scherzer M-L, Hubatsch DA, Frezzotti P. Brinzolamide $1 \% /$ timolol versus dorzolamide $2 \% /$ timolol in the treatment of open-angle glaucoma or ocular hypertension: prospective randomized patient-preference study. Clin Ophthalmol. 2015;9:2263-2270. doi:10.2147/OPTH.S88891 
31. Lerner SF, Park KH, Hubatsch DA, Erichev V, Paczka JA, Roberts TV Efficacy and tolerability of travoprost $0.004 \% /$ timolol $0.5 \%$ fixed-dose combination for the treatment of primary open-angle glaucoma or ocular hypertension inadequately controlled with beta-blocker monotherapy. J Ophthalmol. 2017;2017:1917570. doi: $10.1155 / 2017 / 1917570$
32. Hill AB. The environment and disease: association or causation? Proc R Soc Med. 1965;58(5):295-300.

33. Bartlett JD. Ophthalmic Drug Facts. 25th Bartlett JD. Facts \& Comparisons; 2013.

\section{Publish your work in this journal}

Clinical Ophthalmology is an international, peer-reviewed journal covering all subspecialties within ophthalmology. Key topics include: Optometry; Visual science; Pharmacology and drug therapy in eye diseases; Basic Sciences; Primary and Secondary eye care; Patient Safety and Quality of Care Improvements. This journal is indexed on PubMed

Submit your manuscript here: https://www.dovepress.com/clinical-ophthalmology-journal
Central and CAS, and is the official journal of The Society of Clinical Ophthalmology (SCO). The manuscript management system is completely online and includes a very quick and fair peer-review system, which is all easy to use. Visit http://www.dovepress.com/ testimonials.php to read real quotes from published authors. 